\title{
Action Potential Initiation Site Depends on Neuronal Excitation
}

\author{
Rosemary Melinek and Kenneth J. Muller \\ Department of Physiology and Biophysics, University of Miami Medical School, Miami, Florida 33136
}

The initiation site in neurons is where the excitatory and inhibitory inputs sum to generate action potentials. It is generally considered to be at a fixed location, typically at the axon hillock or initial segment, although action potentials, or impulses, could in theory arise at a site that shifts dynamically. The data reported here show that the initiation site can shift in a graded manner, by as much as $175 \mu \mathrm{m}$, depending on the level of neuronal excitation. Laser axotomy reveals that the Anterior Pagoda (AP) neuron of the leech is excitable within the synaptic neuropil before its axon bifurcates. Using an electrophysiological technique to measure relative delays in impulses arriving at different sites, we have found that depolarization, either by applied current or by synaptic input, can shift the site of impulse initiation in the cell proximally toward the soma and neurites receiving synaptic input. Impulse initiation in this region should enhance the efficacy of inputs synapsing there. Conversely, hyperpolarization can shift the initiation site distally. A shifting initiation site, therefore, may be a mechanism by which synaptic inputs can rapidly enhance or suppress the active response of the AP neuron to other synaptic inputs.

Key words: laser axotomy; dendritic action potential; leech; synaptic integration; impulse initiation site; postsynaptic regulation
To understand how incoming signals are integrated in neurons, it is important to determine where in a neuron action potentials are initiated. In many vertebrate neurons, including motoneurons, the action potential initiation site is found at the initial segment or axon hillock (Eccles, 1964; Waxman and Quick, 1978; Carras et al., 1992; Stuart and Sakmann, 1994), a spccialized region with a high density of sodium channels (Wollner and Catterall, 1986; Angelides et al., 1988). However, in some neurons (Kriebel et al., 1969; Waxman and Quick, 1978), including certain invertebrate neurons, the impulse can initiate at a distance from the soma (Stuart, 1970; Pitman et al., 1972; Pearson and Fourtner, 1975; Heitler and Goodman, 1978; Granzow et al., 1985; Meyrand et al., 1992). In these cells, a number of conditions, including the geometry of the cell and the extent of its proximal excitability, may determine the initiation site (Moore et al., 1983), which in theory can shift dynamically (Moore and Westerfield, 1983). It is possible for a neuron to have more than one initiation site, depending on the presynaptic signal (Korn and Bennett, 1975; Meyrand et al., 1992). The initiation site may depend also on the recent firing of the postsynaptic cell (Calabrese, 1980). Moreover, the observation that action potentials are back-propagated into the dendrites of mammalian neocortical neurons (Stuart and Sakmann, 1994) suggests a mechanism by which the postsynaptic cell may regulate future synaptic input (Hounsgaard and Midtgaard, 1989a).

In many neurons, the soma and dendrites do not support action potentials (Kandel, 1976; Krauthamer and Ross, 1984). Laser axotomy of the leech annulus erector (AE) motoneuron has shown that it is not excitable along its axon proximal to the initiation zone, several hundred micrometers from the cell soma

Received Dec. 11, 1995; revised Jan. 24, 1996; accepted Jan. 26, 1996.

This work was supported in part by National Science Foundation Grant IBN9209769, National Institutes of Health Training Grant T 32 NS07055, and National Institutes of Health Grant R01NS34927. We thank Drs. David Landowne and Gabriel David for useful comments on an earlier version of this manuscript.

Correspondence should be addressed to Kenneth J. Muller, Department of Physiology and Biophysics, University of Miami Medical School, 1600 NW 10th Avenue, R-430, Miami, FL 33136.

Copyright (C) 1996 Society for Neuroscience $0270-6474 / 96 / 162585-07 \$ 05.00 / 0$
(Gu et al., 1991), including the region of its dendrites (Muller and McMahan, 1976). Whereas for many preparations it is not possible to pinpoint the exact site of impulse initiation, the leech offers this distinct advantage. Using accurate electrophysiological recording from the soma and branches of single AE motoneurons, we located the initiation site at the primary axon bifurcation several hundred micrometers from the soma (Gu et al., 1991).

The Anterior Pagoda (AP) cell of the leech is an effector that might modify sensory signals (Gan and Macagno, 1995). Impulses in both the AE and the AP neurons are generated at a distance from the soma and spread only electrotonically into it; thus, the impulses recorded at the soma are small (Kuffler and Potter, 1964; Granzow et al., 1985; Lytton and Kristan, 1989; Gu et al., 1991).

\section{MATERIALS AND METHODS}

Midbody ganglia of the medicinal leech (Hirudo medicinalis) were dissected with their segmental roots intact, pinned on silicone rubber (SYLGARD-184, Dow Corning, Corning, NY)-coated Petri dishes containing leech Ringer's (Nicholls and Baylor, 1968) of the following composition (in $\mathrm{mm}$ ): $\mathrm{NaCl} 115 ; \mathrm{KCl} 4 ; \mathrm{CaCl}_{2} 1.8$; Tris-Inaleate $10, \mathrm{pH} 7.4$. Forty-seven ganglia were used for the laser axotomy experiments, and $\sim 40$ for the electrophysiology experiments, from $\sim 35$ animals.

Laser axotomy. The basic method of Gu et al. (1989) was used. A 1:3 mixture of $20 \mathrm{mg} / \mathrm{ml}$ horseradish peroxidase (HRP; Sigma type VI, St. Louis, MO) in $0.2 \mathrm{M} \mathrm{KCl}$ containing $2 \mathrm{mg} / \mathrm{ml}$ Fast Green FCF (Fisher, Fairlawn, NJ) and $0.2 \mathrm{M}$ 6-carboxyfluorescein dye (6-CF; Molecular Probes, Eugene, OR), $\mathrm{pH} 7.4$, was microinjected under pressure into AP cells, which were then irradiated $\sim 10$ min later. The Fast Green remained in the soma and was a marker for the progress of the injection, which took a few seconds. 6-CF diffused faster than HRP, so at the time that the cells were cut, little HRP had diffused into the irradiated region. The laser beam from a $35 \mathrm{~mW}$ argon laser (Lexel, Palo Alto, CA), operated at $20 \mathrm{~mW}$, was attenuated $\sim 10$-fold with neutral density filters and focused through a Zeiss WL epifluorescence microscope onto a spot $\sim 5 \mu \mathrm{m}$ in diameter (Zeiss, Thornwood, NY). Two hours later, the resealed cells were impaled with an intracellular microelectrode of resistance $15-30 \mathrm{M} \Omega$ containing $4 \mathrm{M}$ potassium acetate. To test their ability to generate action potentials, the cells were depolarized by passing current into the soma through the recording microelectrode using a bridge circuit. The ganglia were then fixed in $2 \%$ glutaraldehyde in $0.1 \mathrm{M}$ sodium phosphate buffer, reacted with benzidine dihydrochloride and $\mathrm{H}_{2} \mathrm{O}_{2}$, 
dehydrated in ethanol, and mounted in Permount (Fisher) (Muller and McMahan, 1976).

Electrophysiological triangulation. The timing of impulses propagating from the bifurcation after antidromic stimulation of one branch was compared with that of impulses arising spontaneously. The arrangement of electrodes has been described previously (Gu et al., 1991) and is shown in Figure 2. Either the posterior or the anterior root was stimulated antidromically with an extracellular suction electrode, and a suction electrode on the other root was used for recording. Extracellular signals were amplified with a Grass P-15 amplifier. All signals were filtered at 5 $\mathrm{kHz}$ with a $24 \mathrm{~dB} /$ octave filter (model 4302, Ithaco, Ithaca, NY), digitized with a TL-1/125 interface, and analyzed with Axotape 2.0 (Axon Instruments, Foster City, CA). The interval between the time of arrival of action potentials reaching the extracellular electrode and the intracellular microelectrode in the soma was measured and designated as $i_{\mathrm{b}}$ because they propagated to the recording sites via the axonal bifurcation. The interval between action potentials arising spontaneously was denoted $i_{\mathrm{s}}$. Between 10 and 40 sweeps were collected in each experiment, and their average value and SD were used in calculating the intervals. In experiments in which the difference between $i_{\mathrm{b}}$ and $i_{\mathrm{s}}$, defined as $\Delta i$, was determined, the SD was calculated by the formula $\left\{\left[S D\left(i_{\mathrm{b}}\right)\right]^{2}\right.$ । $\left.\left[S D\left(i_{\mathrm{s}}\right)\right]^{2}\right\}^{1 / 2}$, where $S D\left(i_{\mathrm{b}}\right)$ is the standard deviation for $i_{\mathrm{b}}$ and $S D\left(i_{\mathrm{s}}\right)$ is the standard deviation for $i_{\mathrm{s}}$. When cells were depolarized or hyperpolarized, it was by direct current injection through a bridge circuit. In some experiments, the ipsilateral connective was also stimulated with an extracellular electrode (see Fig. 2).

\section{RESULTS}

\section{Proximal extent of excitability}

As one step toward determining the site of impulse initiation, it is useful to examine those areas of a neuron that are electrically excitable. This has been done successfully by selectively paring excitable regions of the neuron with a laser microbeam and testing for excitability in the remaining portion after resealing ( $\mathrm{Gu}$ et al., 1991).

The laser microbeam was focused at one of several points along the dye-filled AP-cell axon or primary neurite, and a cut made. After $2 \mathrm{hr}$, the cell was reimpaled and injected with current to determine its ability to generate impulses. The ganglion was then fixed, and the HRP was developed to determine the extent of the axotomy (Fig. 1). Because 6-CF diffuses faster than HRP, little HRP had diffused into the irradiated region at the time the cut was made. Excitability was usually retained when the first flexion (asterisk in Fig. $1 D)$, a region $95 \pm 33 \mu \mathrm{m}(n=5)$ proximal to the primary bifurcation ( $b$ in Fig. $1 D$ ), was spared. Thus, as Figure $1 D$ shows, of the 18 cells in which the primary neurite was cut proximal to the flexion, only 2 generated action potentials, whereas of the 19 cells cut distal to the flexion, 16 generated action potentials. Of 10 controls that were irradiated but not cut, 9 generated action potentials. Input resistance in control AP cells ranged from 12 to $30 \mathrm{M} \Omega$ and was in the same range after axotomy (Fig. 1); thus, loss of excitability was not merely an effect of injury. Moreover, damage that simply reduced input resistance typically incrcased the spontancous firing rate in AP cells. Most significantly, AP cells were excitable in a region proximal to the primary axon bifurcation where neurons with a similar structure and physiology to the AP cell receive synaptic input (Muller and McMahan, 1976) (Fig. 1). An important question, therefore, was whether the initiation site in the AP cell is in the excitable region proximal to the bifurcation.

\section{Site of impulse initiation}

The impulse initiation site for a neuron with a branched axon can be determined by measuring the difference in time of arrival of the action potential at the soma and at one root axon, using an electrophysiological triangulation method (Gu et al., 1991). The timing of arrival of impulses propagating from the bifurcation after antidromic stimulation of the other root is compared with the arrival time of those originating spontaneously or synaptically (Gu et al., 1991). The arrangement of the electrodes for this experiment is shown in Figure 2, and a typical recording of a spontaneously arising impulse is shown in the inset. When one of the roots is stimulated, for example the anterior root ( $a$ in Fig. 2), an action potential is initiated there that propagates into the ganglion to the primary bifurcation, and from there propagates both to the soma ( $c$ in Fig. 2) and to the posterior root ( $p$ in Fig. 2 ). For antidromic and for spontaneous action potentials, the action potential arrives at the soma before it arrives at the extracellular recording electrode (inset in Fig. 2), and a time interval $i$ is measured between the events at the two electrodes. To compare impulses generated in various ways, the greatest accuracy is obtaincd by measuring the pcak of the intracellular recording and the peak deflection of the extracellular recording. Thus, $i$ recorded for impulses arising from antidromic stimulation at $a$, termed $i_{\mathrm{b}}$, would be the same as $i_{\mathrm{s}}$ for an impulse initiated spontaneously or synaptically at the bifurcation (Gu et al., 1991). Any significant deviation of $i_{\mathrm{s}}$ from $i_{\mathrm{b}}$ would indicate that the impulse did not initiate at the bifurcation. Defining $\Delta i$ as $\left(i_{s}-i_{\mathrm{b}}\right)$, then $\Delta i>0$ when the spontaneous impulse initiates proximal to the bifurcation, and $\Delta i<0$ when the impulse initiates distal to the bifurcation. The value of $\Delta i$ can be converted to distance $D$ from the bifurcation by the formula $D=(1 / 2)(\Delta i) \theta$, where $\theta$ is the conduction velocity. A uniform conduction velocity was assumed along the length of the axon, and was measured as $0.16 \pm 0.06$ $\mathrm{m} / \mathrm{sec}(n=13)$, so a $\Delta i$ of +1 msec would represent action potential initiation at a site $\sim 80 \mu \mathrm{m}$ proximal to the primary bifurcation. Error or variability in the conduction velocity is reflected as uncertainty in the distancc of initiation from the bifurcation.

The initiation sites for $18 \mathrm{AP}$ cells, measured at their resting potential, were found to be chiefly at the bifurcation (Fig. 3), although some initiation sites were more proximal. There was no obvious relationship between those initiation sites and the resting potential of the cell. In contrast, when AP cells were depolarized or hyperpolarized by current injected through the recording microelectrode, the initiation site shifted proximally or distally, respectively. This is illustrated for a typical experiment in Figure 4, in which the delays $i_{\mathrm{s}}$ and $i_{\mathrm{b}}$ at the resting potential $(-41 \mathrm{mV})$ were identical ( $A$ and $D$, respectively). Whereas $i_{\mathrm{h}}$ changed little with depolarization $(E,-37 \mathrm{mV})$ or hyperpolarization $(F,-58$ $\mathrm{mV}), i_{\mathrm{s}}$ increased $(B)$ and decreased $(C)$ substantially with the same depolarization and hyperpolarization. Because the delay for impulses generated by antidromic stimulation $\left(i_{\mathrm{b}}\right)$ remained steady, the shift caused by current injection was not attributable to a change in conduction velocity. Figure 5 summarizes recordings from $6 \mathrm{AP}$ cells. The maximum proximal shift from the branchpoint, shown in the graph, is $175 \mu \mathrm{m}$ for a cell depolarized to -28 $\mathrm{mV}$. The slope of the regression line indicates a shift of the initiation site by $6.1 \pm 1.2 \mu \mathrm{m} / \mathrm{mV}$, assuming a conduction velocity of $0.16 \mathrm{~m} / \mathrm{sec}$, so a $10 \mathrm{mV}$ depolarization would shift the initiation site proximally an average of $61 \_12 \mu \mathrm{ml}$.

A series of measurements of only spontaneously arising impulses (Fig. 6) confirmed the shift in delay with depolarization and hyperpolarization. Although the initiation site could not be determined, because $i_{\mathrm{b}}$ was not known in these experiments, the relative shift from resting potential could be calculated. The average shift from these points gave a value of $1.0 \pm 0.10 \mathrm{msec}$ per $10 \mathrm{mV}$ of depolarization. For the 8 cells hyperpolarized by this amount, the average shift was $-0.90 \pm 0.10 \mathrm{msec}$. These results 

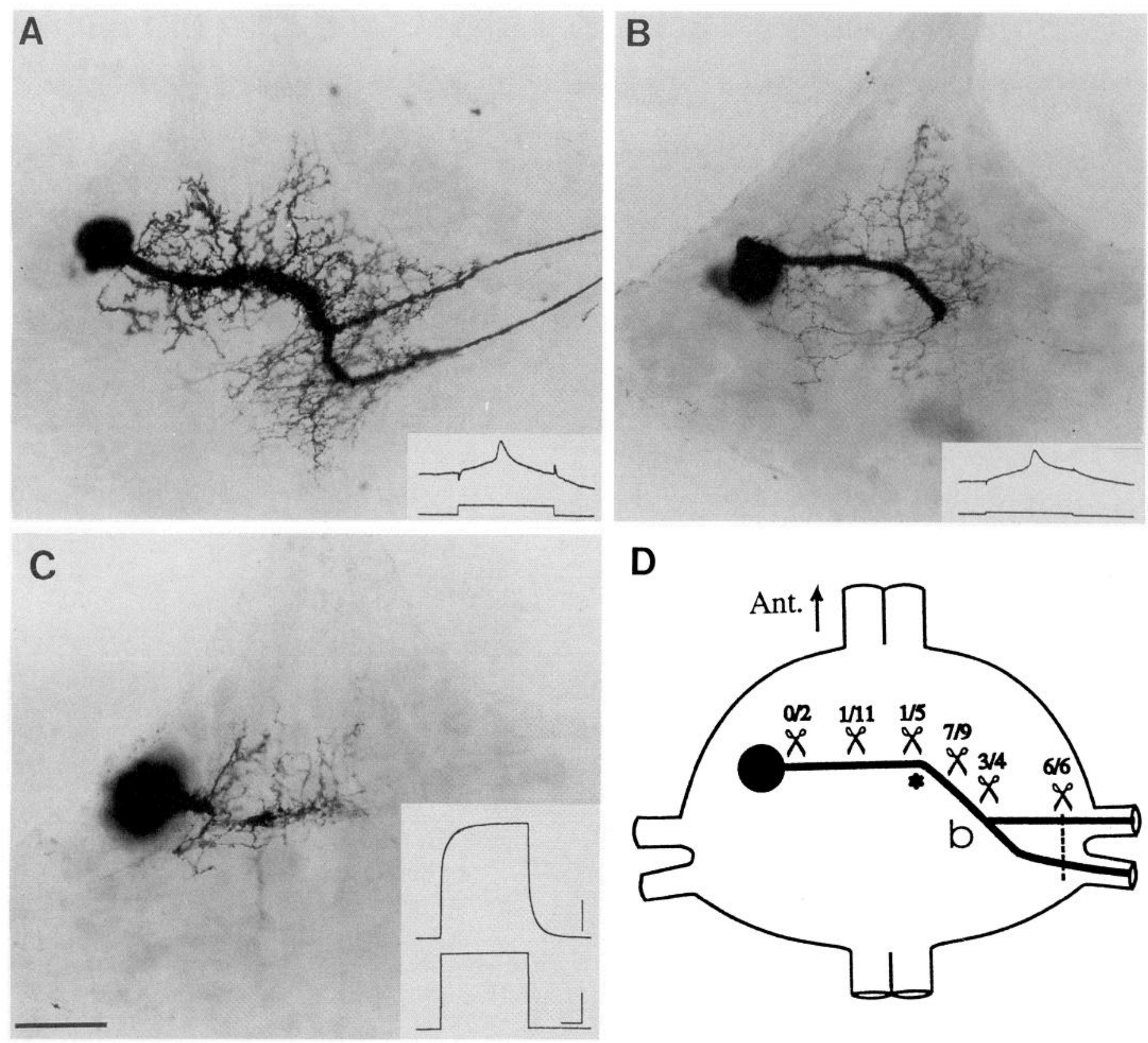

Figure 1. Laser microsurgery of AP cells. A, An uncut AP cell. Inset, Recording of an action potential evoked in an AP cell (top trace) by depolarizing current (bottom trace). Calibration bar (shown in $C$ ): top trace, $10 \mathrm{mV}$; bottom trace, $0.5 \mathrm{nA}$. Time scale: 10 msec. $B$, Action potentials could be evoked in this cell, which was cut distal to the first flexion (asterisk in $D$ ). $C$, Action potentials could not be evoked in this cell even by stronger stimuli. Scale bar: $100 \mu \mathrm{m}$ (same for $A$ and $B$ ). $D$, Schematic diagram of an AP cell within a ganglion shows where laser cuts were made. The values above scissors indicate the fraction of the number of cells cut at each region that generated action potentials, with the total number at each location given in the denominator. Of 10 cells filled and irradiated but not cut, 9 had action potentials.

show that depolarization of the soma shifted the site of impulse initiation $\sim 80 \pm 8 \mu \mathrm{m}$ proximally along the excitable membrane toward the soma for a $10 \mathrm{mV}$ depolarization. Hyperpolarization shifted it by about the same amount in the reverse direction along the axon. In this experiment, only $i_{\mathrm{s}}$ was considered; the SD was small for each point, suggesting that there was a single initiation site at each potential. In Figures 4 and $5, \Delta i$ rather than $i_{\mathrm{s}}$ alone was the dependent variable, and the method of calculating its SD (see Materials and Methods) masked the small SD of the individual $i_{\mathrm{s}}$ or $i_{\mathrm{b}}$.

\section{Shift in initiation site by synaptic input}

One natural source of depolarization is synaptic excitation. To test whether synaptic input could shift the initiation site, the ipsilateral anterior connective was stimulated using an extracellular suction electrode (Figs. 2, 7A). This connective contains sensory axons, some of which terminate proximal to the branch point of the AP cell, as diagrammed in Figure 2 (Muller and McMahan, 1976; Muller, 1979), where they apparently synapse, exciting the AP cell (Sunderland, 1980). As shown in Figure $7 A$, after the connective was stimulated with a series of three shocks to excite the sensory 


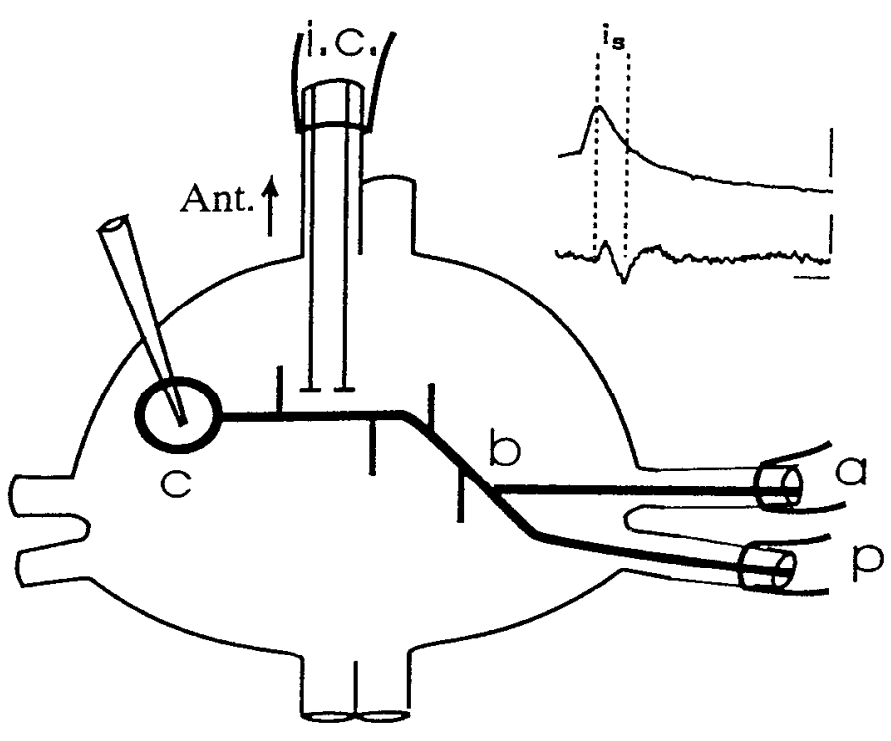

Figure 2. An arrangement of electrodes for electrophysiological recording. Antidromic stimulation of either the posterior $(p)$ or the anterior $(a)$ root initiated an action potential that was recorded at the cell soma and at the other root. The interval $\left(i_{\mathrm{b}}\right)$ between the time of arrival of action potentials reaching the extracellular suction electrode at the root and the intracellular microelectrode at the soma $(c)$ was measured. This delay was also measured for spontaneously arising action potentials and denoted $i_{s}$. In some experiments, an additional suction electrode was placed on the ipsilateral connective (i.c.) to stimulate the cell synaptically and the delay (also denoted $i_{s}$ ) measured. Inset, The top trace shows a spontaneous action polential measured with a microelectrode in the soma. Calibration bar: $5 \mathrm{mV}$. The bottom trace is the corresponding action potential recorded at the posterior root with an extracellular suction electrode. Calibration bar: $0.1 \mathrm{mV} . i_{s}$ is $4.6 \mathrm{msec}$ in this trace. Horizontal calibration bar: $5 \mathrm{msec}$.

neurons and a response was obtained, the anterior root was immediately stimulated to verify that there was no change in conduction velocity or related properties. The $\Delta i$ was markedly greater for all six preparations in which the ipsilateral connective was stimulated (Fig. $7 B$ ), indicating that the initiation site was shifted proximally from the bifurcation. The proximal shift for synaptic stimulation ranged from 32 to $64 \mu \mathrm{m}$. Stimulating the sensory and other axons of the connective appeared not to have had a long-lasting effect in shifting the initiation site, because spontaneous impulses recorded minutes after connective stimulation arose close to the bifurcation in most cases (Fig. $7 B$ ). In only one cell (cell 6 in Fig. $7 B$ ) was the spontaneous impulse shifted to the same extent as the synaptically driven impulse, which was already proximal to the axon bifurcation.

\section{DISCUSSION}

The AP cell action potential initiation site can be shifted with current injection. This is in contrast to another leech motoneuron, the AE cell, and most vertebrate motoneurons, in which action potential initiation apparently occurs at a fixed site. However, it may be that a shift does occur in other leech motoneurons. The AP cell structure is typical of leech excitatory motoneurons (Muller and McMahan, 1976; Muller, 1979) and is distinct from the other classes of neurons, such as mechanosensory cells (Muller and McMahan, 1976), heart interneurons (Tolbert and Calabrese, 1985), and inhibitory motoneurons (Muller, 1979), all of which are presynaptic within the ganglion and the synaptic varicosities of which, described in electron microscopic studies, are distinctive in the light microscope. Among the distinguishing features of the

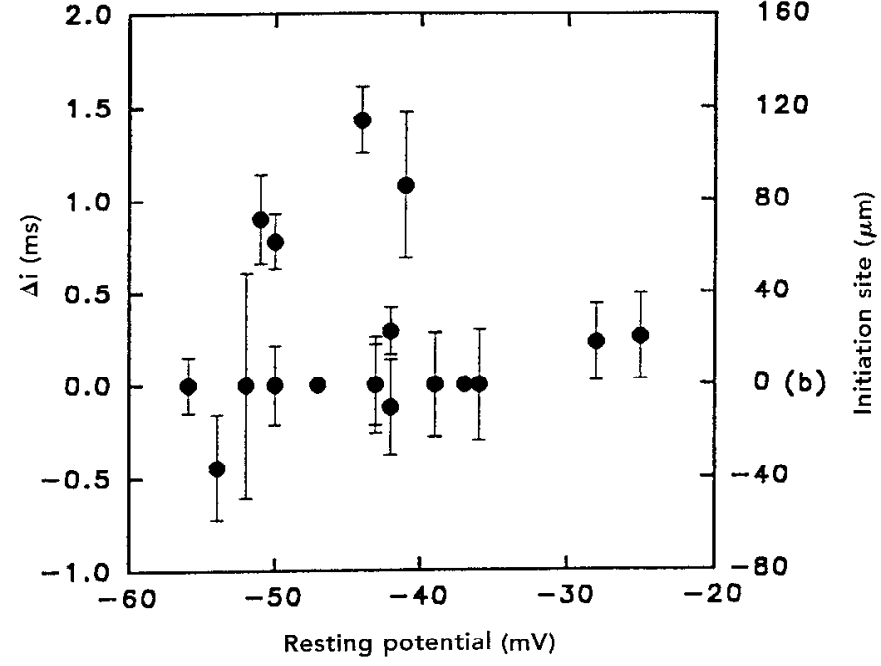

Figure 3. Initiation sites in AP cells. Timing of action potentials was measured in $18 \mathrm{AP}$ cells at their resting potentials, and $\Delta i=\left(i_{\mathrm{s}}-i_{\mathrm{b}}\right)$ calculated and converted to the distance of the action potential initiation site from the primary bifurcation. This distance is shown on the right ordinate. Positive numbers indicate a proximal shift from the bifurcation; negative numbers indicate a distal shift. Each point is an average of $10-40$ sweeps. Error bars represent the SD in this and the following graph. There was no apparent relationship between resting potential and initiation site, which for most cells was at the bifurcation $(b)$.

motoneurons, the primary neurite, or axon, of which crosses the ganglion and exits via contralateral roots, is an extensive arbor of neurites receiving synaptic input and free of varicosities (Muller and McMahan, 1976), an inexcitable soma (Stuart, 1970), and a cholinergic phenotype (Wallace, 1981). The AP cell is also cholinergic (Wallace, 1981), varicosities are not observed on the AP cell in the ganglion ( $K$. Muller, unpublished observations), and it responds to sensory input as a motoneuron (Sunderland, 1980).

Because of its association with sensory processes in the periphery, the AP cell might modify sensory signals (Wolszon et al., 1994; Gan and Macagno, 1995), and as such it could have an apparatus for integrating inputs that is different from that of the $\mathrm{AE}$ cell. The results of laser axotomy show that the proximal extent of the AP cell's excitability is greater than that of the AE cell and includes a general region of its neurite arborization, where synaptic inputs are thought to be concentrated. Although it is unknown whether the arborizing branches of the AP cell are excitable, excitable dendrites have been reported in the mammalian CNS (Spencer and Kandel, 1961; Llinas and Sugimori, 1980; Hounsgaard and Midtgaard, 1989b; Stuart and Sakmann, 1994) and in some invertebrate neurons (Calabrese and Kennedy, 1974; Krauthamer and Ross, 1984). The distribution of excitability in the AP cell indicates that the proximal arborization may be a site of regulation of synaptic input, as is thought to occur in other preparations (Llinas and Sugimori, 1980; Stuart and Sakmann, 1994). For neocortical and hippocampal neurons, impulses can propagate back into the dendritic region from an initiation site near the axon initial segment (Richardson et al., 1987; Spruston et al., 1995). There is also evidence from hippocampal neurons that the initiation site may shift into the dendritic region under some circumstances (Turner et al., 1991).

There are vertebrate and invertebrate preparations in which multiple impulse initiation sites have been described. Korn and Bennett (1975) reported two different initiation sites in fish ocu- 

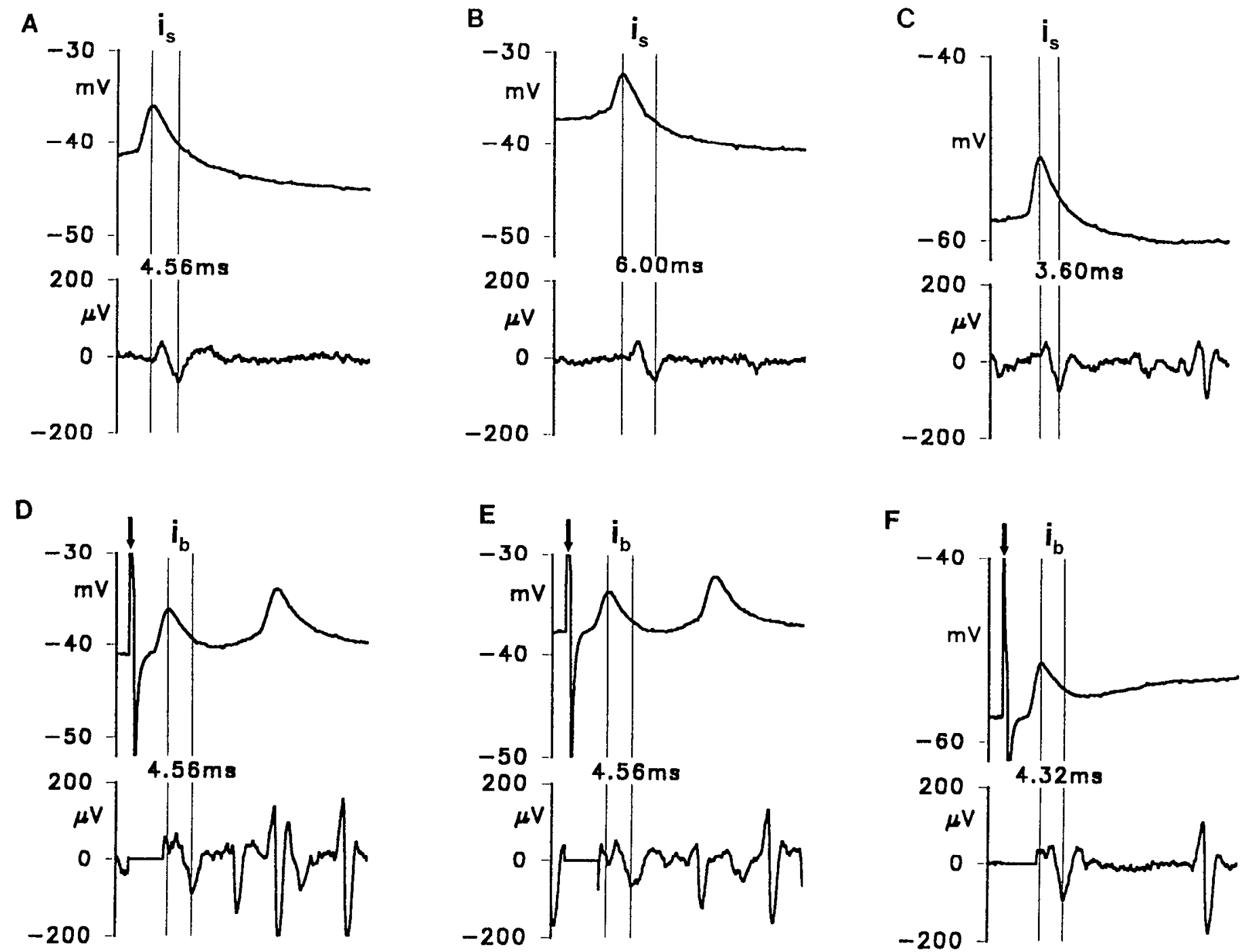

Figure 4. Shift in initiation site with current injection. Each trace shows the interval, $i$, between the time of arrival of the action potential at the intracellular electrode (top trace) and the extracellular recording electrode (bottom trace). In the lower trace of $D-F$, the stimulus artifact was reduced for clarity. In $A-C$, the action potentials arose spontaneously, with the time interval between the pcak of the intracellular action potential and the peak deflection of the extracellular action potential denoted $i_{3} . D-F$ were evoked by antidromic stimulation of the anterior root, and the time interval denoted $i_{b}$. The truncated stimulus artifact is indicated by arrows. The second action potential in $D$ and $E$ was caused by a synaptic potential in response to the stimulation. $A, D$, The cell was at its resting potential, and both $i_{s}$ and $i_{b}$ were $4.56 \mathrm{msec} . B, E$, The cell was depolarized and $i_{s}$ increased, although $i_{b}$ remained constant, indicating that there was no change in conduction velocity. $C, F$, The cell was hyperpolarized and $i_{s}$ decreased, but $i_{b}$ remained constant.

lomotor neurons, depending on the modality of the sensory input. Single heart interneurons in the leech have multiple initiation sites, located in different ganglia, that are controlled by the pattern of impulse activity of a dominant primary initiation site (Calabrese, 1980). The mechanism for the shift of the initiation site is different from that reported here, because very strong hyperpolarizing currents injected into the cell body failed to affect the initiation site. In a model of their findings to explain a secondary initiation site in the lateral gastric motoneuron of the crab, produced by application of serotonin (Meyrand et al., 1992), Kepler and Marder (1993) have shown that a slow regenerative conductance could result in an additional action potential initiation site. However, our results do not indicate an additional initiation site but, rather, a shift in a single initiation site.

Although spontaneous impulses could arise as a result of syn- aptic input throughout the central arborization of the cell, and therefore might be expected to initiate at various locations depending on the level of spontaneous presynaptic activity, in fact there was little scatter in the site of spontaneous impulse initiation at a particular resting potential, suggesting a single initiation site. Another interpretation of these data is that action potentials are initiated in various processes emerging from the prinlary neurite or axon at a single site at which they converge before propagating along the axon. However, this would appear to be inconsistent with the data, which show a graded shift of the initiation site along the axon or primary neurite, depending on the level of excitation of the cell.

In a model by Moore et al. (1983) of a neuron with a uniform distribution of sodium channels, two important factors that were shown to determine the initiation site are the fraction of the 


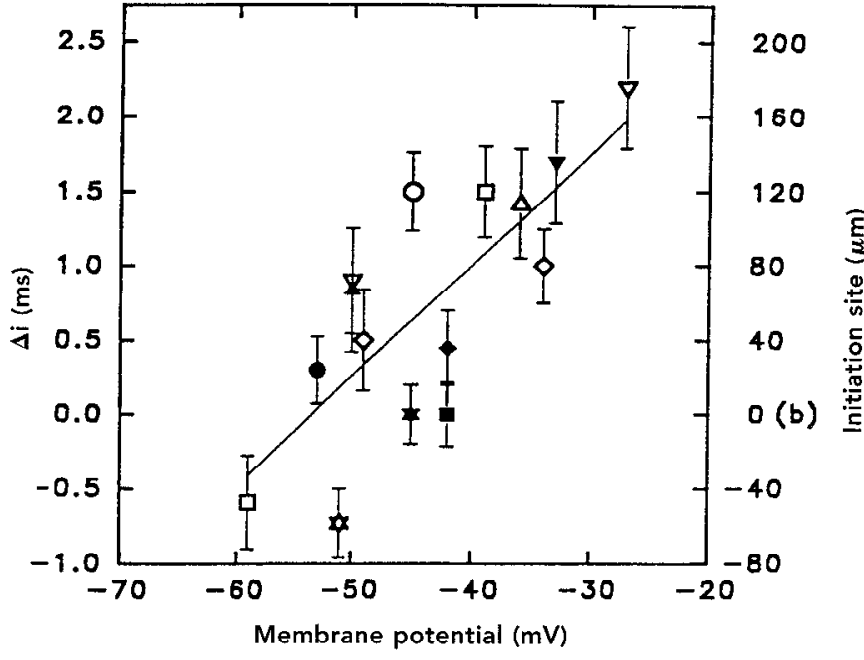

Figure 5. Six AP cells were depolarized or hyperpolarized from rest by current injection into the soma. Each cell is represented by a different symbol. Filled symbols mark the recordings at resting potential. Depolarization shifted the initiation site proximally; hyperpolarization shifted it distally. The regression line has a coefficient, $R$, of 0.77 and a slope of 6.1 $\pm 1.2 \mu \mathrm{m} / \mathrm{mV}$.

dendritic tree with excitable membrane and the stimulus strength. With an extended region of excitability, depolarizing the cell by current injection or synaptic input could decrease the threshold for the action potential, bringing the cell to threshold closer to the soma. Conversely, hyperpolarizing the cell will increase the threshold and move the initiation site further away from the soma. Thus, a shifting initiation site is a means by which the effects of certain inputs might be regulated in the postsynaptic cell, independently of changes in synaptic strength that are frequently considered to underlie synaptic plasticity (Davis and Murphey, 1994). It may be expected that excitatory and inhibitory synaptic

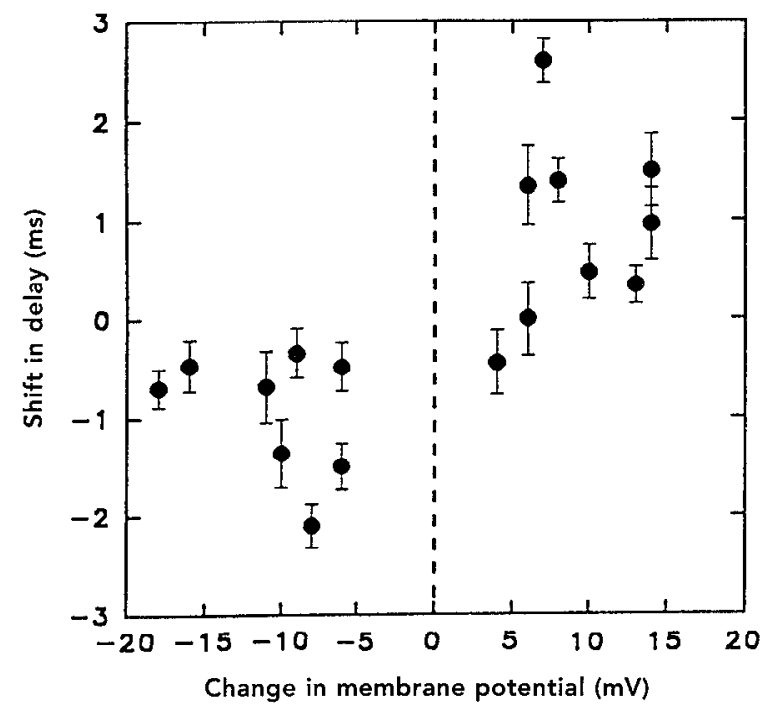

Figure 6. Shift in $i_{\mathrm{s}}$ with change in membrane potential. Experiments measuring only $i_{\mathrm{s}}$ confirmed the shift in delay with current injection. The graph shows that in 9 cells depolarized from their resting potential $(0$ on the ordinate), the interval $i_{\mathrm{s}}$ was increased. The mean of these points indicated an average shift of $1.0 \pm 0.1 \mathrm{msec}$ per $10 \mathrm{mV}$ of depolarization. For 8 cells hyperpolarized from their resting potential, the average decrease in $i_{\mathrm{s}}$ was $0.9 \pm 0.1 \mathrm{msec}$ per $10 \mathrm{mV}$ hyperpolarization.
A

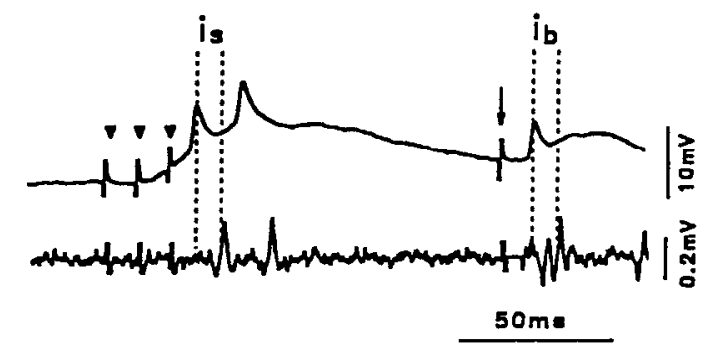

$\mathbf{B}$

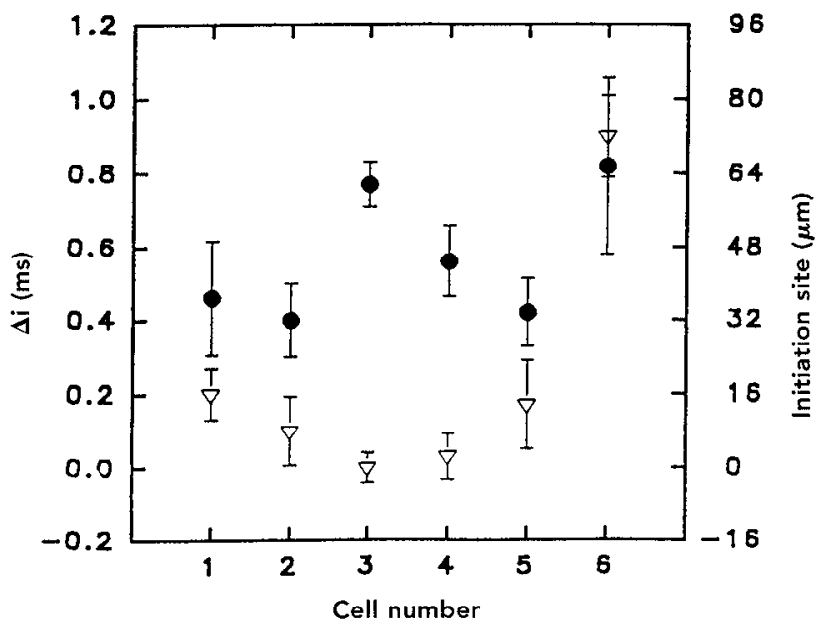

Figure 7. Initiation site for synaptically evoked action potentials. $A$, The ipsilateral connective was stimulated with three shocks at $100 \mathrm{~Hz}$ (arrowheads in top trace) once every $10 \mathrm{sec}$. After the connective stimulation, the anterior root was stimulated (single arrow) to verify that there was no change in the conduction velocity or related properties. Stimulus artifacts were reduced for clarity of presentation. The top trace shows the intracellular recording; the bottom trace shows the corresponding extracellular recording at the posterior root. The interval between the intracellular and the extracellular recording for the connective stimulation, indicated by $i_{s}$ in the figure, was $8.0 \mathrm{msec}$, longer than for the root stimulation, indicated by $i_{b}$ in the figure, which was $7.2 \mathrm{msec} . B$, The $\Delta i$ for synaptically evoked action potentials is represented by filled circles in the graph and for spontaneously arising impulses by inverted open triangles in the graph. Between 10 and 40 sweeps were averaged and subtracted for each point. The error bar shows the SEM. Distance from the bifurcation is shown on the right ordinate. Positive numbers indicate a proximal shift from the bifurcation; negative numbers a distal shift. Most of the spontaneous action potentials arose within $-20 \mu \mathrm{m}$ of the bifurcation. Stimulating the anterior connective moved the initiation site closer to the soma in most cases.

inputs would interact, not simply by adding and subtracting in driving the membrane toward and away from threshold, but also by effectively changing the threshold by shifting the initiation site. Thus, a proximal shift could increase the probability of additional excitatory inputs close to the new initiation site reaching threshold; conversely, a distal shift may selectively reduce their effectiveness.

\section{REFERENCES}

Angelides KJ, Elmer LW, Loftus D, Elson E (1988) Distribution and lateral mobility of voltage-sensitive sodium channels in neurons. J Cell Biol 106:1911-1925.

Calabrese RL (1980) Control of multiple impulse-initiation sites in a leech interneuron. J Neurophysiol 44:878-896.

Calabrese RL, Kennedy D (1974) Multiple sites of spike initiation in a single dendritic system. Brain Res 82:316-321. 
Carras PL, Coleman PA, Miller RF (1992) Site of action potential initiation in amphibian ganglion cells. J Neurophysiol 67:292-303.

Davis GW, Murphey RK (1994) Long-term regulation of short-term transmitter release properties: retrograde signaling and synaptic development. Trends Neurosci 17:9-13.

Eccles JC (1964) The physiology of synapses, pp 1-316. Berlin: Springer.

Gan WB, Macagno ER (1995) Developing neurons use a putative pioneer's peripheral arbor to establish their terminal fields. J Neurosci 15:3254-3262.

Granzow B, Friesen WO, Kristan Jr WB (1985) Physiological and morphological analysis of synaptic transmission between leech motor neurons. J Neurosci 5:2035-2050.

Gu X, Macagno ER, Muller KJ (1989) Laser microbeam axotomy and conduction block show that electrical transmission at a central synapse is distributed at multiple contacts. J Neurobiol 20:422-434.

Gu X, Muller KJ, Young SR (1991) Synaptic integration at a sensory motor reflex in the leech. J Physiol (Lond) 441:733-754.

Heitler WJ, Goodman CS (1978) Multiple sites of spike-initiation in a bifurcating locust neurone. J Exp Biol 76:63-84.

Hounsgaard J, Midtgaard J (1989a) Dendrite processing in more ways than one. Trends Neurosci 12:313-315.

Hounsgaard J, Midtgaard J (1989b) Synaptic control of excitability in turtle cerebellar Purkinje cells. J Physiol (Lond) 409:157-170.

Kandel ER (1976) Cellular basis of behavior: an introduction to behavioral neurobiology, pp 1-727. San Francisco: Freeman.

Kepler TB, Marder E (1993) Spike initiation and propagation on axons with slow inward currents. Biol Cybern 68:209-214.

Korn H, Bennett MVL (1975) Vestibular nystagmus and tcleost oculomotor neurons: functions of electrotonic coupling and dendritic impulse initiation. J Neurophysiol 38:430-451.

Krauthamer V, Ross WN (1984) Regional variations in excitability of barnacle neurons. J Neurosci 4:673-682.

Kriebel ME, Bennett MVL, Waxman SG, Pappas GD (1969) Oculomotor neurons in fish: electronic coupling and multiple sites of impulse initiation. Science 166:520-523.

Kutfler SW, Potter DD (1964) Glia in the leech central nervous system: physiological properties and neuron-glia relationship. J Neurophysiol 27:290-320.

Llinas R, Sugimori M (1980) Electrophysiological properties of in vitro Purkinje cells in mammalian cerebellar slices. J Physiol (Lond) 305:197-213.

Lytton WW, Kristan WB (1989) Localization of a leech inhibitory synapse by photo-ablation of individual dendrites. Brain Res 504:43-48.

Meyrand P, Weimann JM, Marder E (1992) Multiple axonal spike initiation zones in a motor neuron: serotonin activation. $J$ Neurosci $12: 2803-2812$.

Moore JW, Westerfield M (1983) Action potential propagation and threshold parameters in inhomogeneous regions of squid axons. J Physiol (Lond) 336:285-300.
Moore JW, Stockbridge N, Westerfield M (1983) On the site of impulse initiation in a neurone. J Physiol (Lond) 336:301-311.

Muller KJ (1979) Synapses between neurones in the central nervous system of the leech. Biol Rev 54:99-134.

Muller KJ, McMahan UJ (1976) 'I'he shapes of sensory and motor neurones and the distribution of their synapses in ganglia of the leech: a study using intracellular injection of horseradish peroxidase. Proc R Soc Lond [Biol] 194:481-499.

Pearson KG, Fourtner CR (1975) Nonspiking interneurons in walking system of the cockroach. J Neurophysiol 38:33-52.

Pitman RM, Tweedle CD, Cohen MJ (1972) Branching of central neurons: intracellular cobalt injection for light and electron microscopy. Science 176:412-414.

Richardson TL, Turner RW, Miller JJ (1987) Action-potential discharge in hippocampal CA1 pyramidal neurons: current source-density analysis. J Neurophysiol 58:981-996.

Spencer WA, Kandel ER (1961) Electrophysiology of hippocampal neurons. IV. Fast prepotentials. J Neurophysiol 24:272 285.

Spruston N, Schiller Y, Stuart G, Sakmann B (1995) Activity-dependent action potential invasion and calcium influx into hippocampal CA1 dendrites. Science 268:297-300.

Stuart AE (1970) Physiological and morphological properties of motoneurones in the central nervous system of the leech. J Physiol (Lond) 209:627-646.

Stuart GJ, Sakmann B (1994) Active propagation of somatic action potentials into neocortical pyramidal cell dendrites. Nature 367:69-72.

Sunderland AJ (1980) A hitherto undocumented pair of neurons in the segmental ganglion of the lecch which receive synaptic input from mechanosensory cells. Comp Biochem Physiol 67:299-302.

Tolbert LP, Calabrese RL (1985) Anatomical analysis of contacts between identified neurons that control heartbeat in the leech Hirudo medicinalis. Cell Tissue Res 242:257-267.

Turner RW, Meyers DER, Richardson TL, Barker JL (1991) The site of action potential discharge over the somatodendritic axis of rat hippocampal CA1 pyramidal neurons. J Neurosci 11:2270-2280.

Wallace BG (1981) Neurotransmitter chemistry. In: Neurobiology of the leech (Muller KJ, Nicholls JG, Stent GS, eds), pp 147-172: Cold Spring Harbor, NY: Cold Spring Harbor Laboratory.

Waxman SG, Quick DC (1978) Functional architecture of the initial segment. In: Physiology and pathobiology of axons (Waxman SG, ed), pp 125-130: New York: Raven.

Wollner DA, Catterall WA (1986) Localization of sodium channels in axon hillocks and initial segments of retinal ganglion cells. Proc Natl Acad Sci USA 83:8424-8428.

Wolszon LR, Rehder V, Kaler SB, Macagno ER (1994) Calcium wave fronts that cross gap junction may signal neuronal death during development. J Neurosci 14:3437-3448. 